\title{
Research Paper: Investigating the Empowerment of the Physically-Handicapped People and Its Related Factors: A Cross-Sectional, Analytical Study in Kohgiluyeh and Boyer-Ahmad Province in 2015
}

\author{
*Vahid Dastyar ${ }^{1}$, Asghar Mohammadi ${ }^{1}$
}

1. Department of Sociology, Faculty of Humanities, Dehaghan Branch, Islamic Azad University, Dehaghan, Isfahan, Iran.

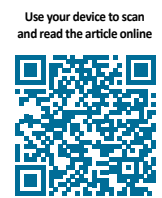

Citertion Dastyar V, Mohammadi A. [Investigating the Empowerment of the Physically-Handicapped People and Its Related Factors: A Cross-Sectional, Analytical Study in Kohgiluyeh and Boyer-Ahmad Province in 2015 (Persian)]. Archives of Rehabilitation. 2019; 19(4):354-369. http://dx.doi.org/10.32598/ri.19.4.354

http://dx.doi.org/10.32598/rj.19.4.354

Received: 23 May 2018 Accepted: 10 Nov 2018 Available Online: 01 Jan 2019

\begin{abstract}
Objective Empowerment is a process that helps the physically-handicapped people to break the poverty loop, achieve self-reliance and self-sufficiency, and join the mainstream of life. This study aimed to investigate the empowerment (sense of meaningfulness, effectiveness, autonomy, self-efficacy and sense of security, and their related factors) of the physically-handicapped people (motor, visceral and sensory disabilities) under the support of Welfare Organization of Kohgiluyeh and Boyer-Ahmad Province in 2015. Materials \& Methods The research method was survey-based; a type of cross-sectional and analytical method. The data collection tool was a researcher-made questionnaire (including four demographic questions (level of education, gender, disability type, and age) and 46 research-specific questions (10 questions about social trust, 9 questions about social participation, 8 questions about sports activity, 4 questions about sympathy behaviors and 15 questions about empowerment of people with disabilities) with 5-point rating Likert-type scale. The statistical population comprised all the physically-handicapped people (motor, visceral, and sensory disabilities) who were under the support of Welfare Organization of Kohgiluyeh and Boyer-Ahmad Province, Iran. They comprised about 10189 people in each city. A total of 370 subjects were selected as a sample using Kokaran formula and then randomized sampling was used between eight cities of Kohgiluyeh and Boyer-Ahmad Province. Therefore, in the first stage, 8 cities were selected. In the second stage, the physically-handicapped people of each city were selected with the help of the welfare organization of the city. In the third stage, a group of physically-handicapped people was randomly selected. In the final stage, they were visited personally. In this study, the validity of the questionnaire was tested through content validity, i.e. by referring to common sense, expert judges, books and related subjects. In other words, a completed questionnaire was delivered to counsellor professor and 10 experts and professors in the field of Methodology, Psychology, and Sociology. Then, their comments and views about indices, reagents and research subjects were taken and the final questionnaire was compiled. In order to assess the reliability of the questionnaire before its final completion, 40 questionnaires were prepared and its alpha values were found using Cronbach method as 0.84 for the empowerment of the people with disabilities, 0.72 for the social trust, 0.77 for the social participation, 0.85 for the sports activity, and 0.90 for the sympathy behaviors. The data analysis was done using descriptive statistics (frequency, percentage, mean, standard deviation, skewness and kurtosis) and inferential statistics (Pearson correlation coefficient tests, variance analysis, $t$ test for two Independent samples, multivariate regression, and path analysis) in SPSS V. 21.
\end{abstract}

\section{* Corresponding Author:}

Vahid Dastyar, MA.

Address: Department of Sociology, Faculty of Humanities, Dehaghan Branch, Islamic Azad University, Dehaghan, Isfahan, Iran.

Tel: +98 (901) 7093104

E-Mail: vdastyar95@gmail.com 
Keywords:

Empowerment, Physically-handicapped people, Social trust, Social participation, Sports activities, Sympathy behaviors
Results Results of the Pearson correlation coefficient analysis indicate a significant relationship between the social trust (with three dimensions of interpersonal trust, generalized trust and institutional trust), social participation (with two dimensions of formal and informal participation) and sports activities (with two dimensions of the promotion of physical and mental health) with the empowerment of the physically-handicapped people $(P<0.001)$. There was no relationship between the variables of age $(P=0.418)$ and sympathy behaviors $(P=0.395)$ with the empowerment of the physically-handicapped people. According to the results of $t$ test in terms of the demographic characteristics of the physically-handicapped people, there was no significant difference between gender and empowerment of the physically-handicapped people $(P=0.756)$. Based on the results of the variance analysis test in terms of the demographic characteristics of the physically-handicapped people, there was no significant difference between the type of disability and empowerment of the physically handicapped people $(P=0.174)$. However, there is a significant difference between the education level and empowerment of the physically handicapped people $(P<0.001)$. People with disability, who were highly educated, had higher empowerment ability. The results of regression test analysis showed that the most important variables affecting the empowerment of the physically-handicapped people were institutional trust $(\beta=0.327)$, environmental trust $(\beta=0.133)$, informal participation $(\beta=0.132)$ and educational level $(\beta=0.118)$. In addition, the variance of the empowerment of the physically-handicapped people was affected by $28 \%$ than the significant independent variables existed in the model. Among the effective variables, social participation had the highest influence on the empowerment of the physically-handicapped people and then social trust, education level and sports activities in the descending order.

Conclusion The study results indicate that four variables of age, gender, type of disability and sympathy behaviors failed to explain the changes of the empowerment of the physically-handicapped people, but four variables of social trust, social participation, sports activities and educational level could explain the changes of the empowerment of the physically-handicapped people. It is recommended that research studies about the empowerment of the physically-handicapped people should be continued in order to better understand the facilitators and barriers to the empowerment of the physically handicapped. 
This Page Intentionally Left Blank 


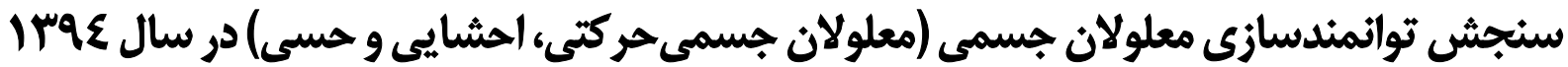

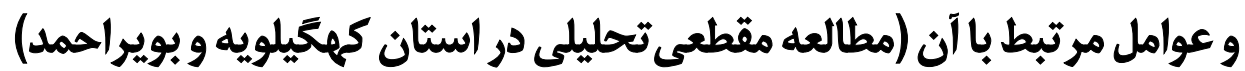

\author{
• وحيد دستيار' • اصغر محمدى'
}

1- كروه جامعهشناسى، دائشكده علوم انسانى، واحد دهاقان، دانشعاه آزاد اسلامى، دهاقان، اصفهان، ايران.

\begin{abstract}
حكبد

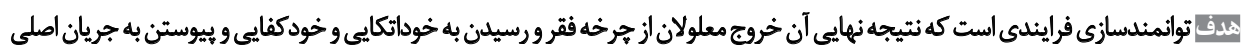

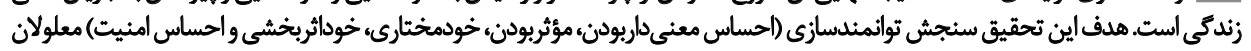

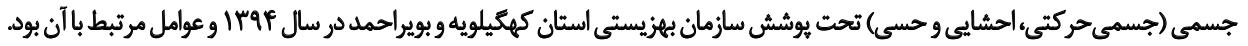

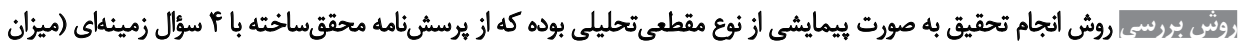

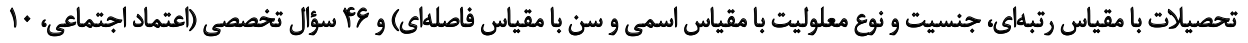

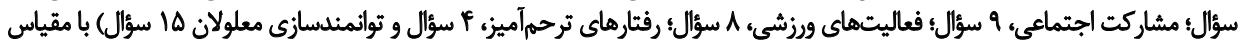

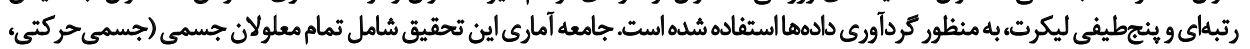

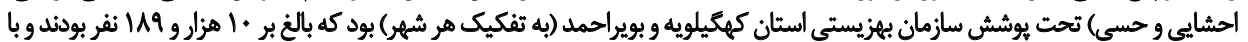

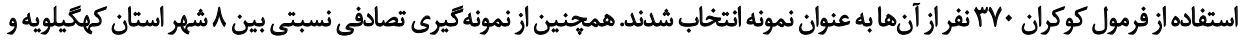

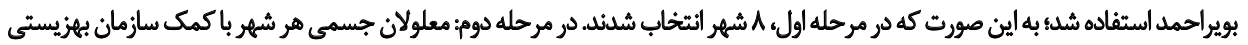

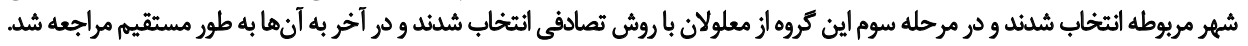

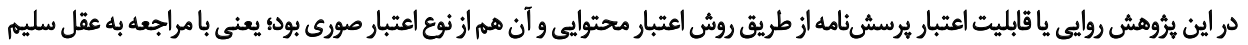

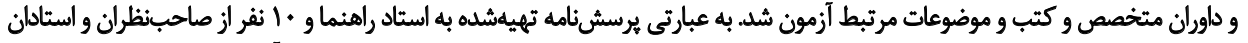

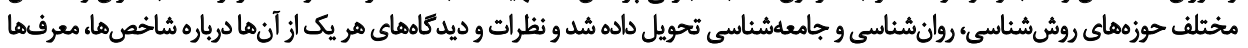

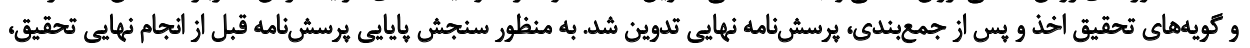

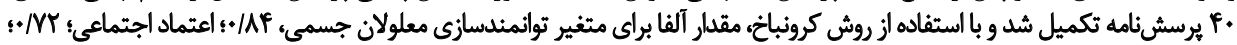

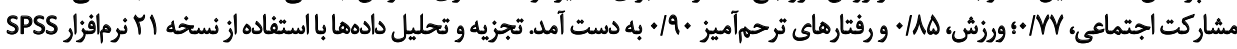

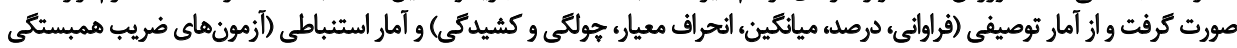

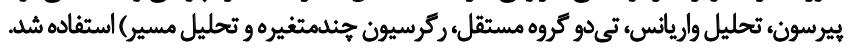

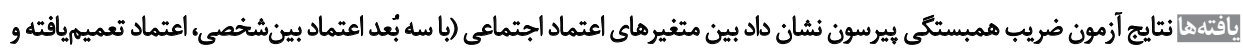

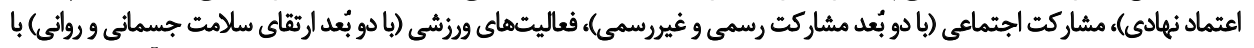

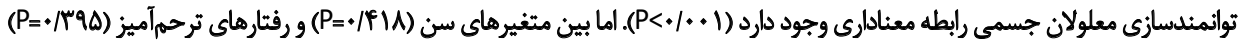

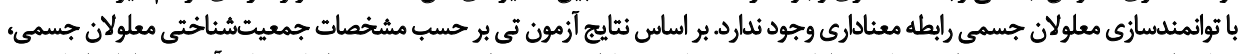

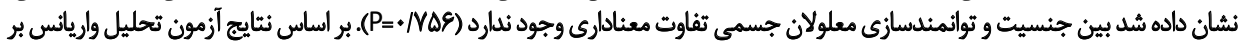

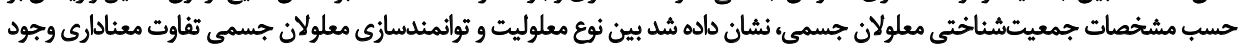

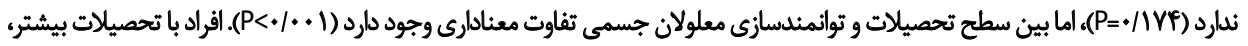

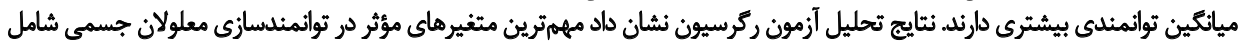

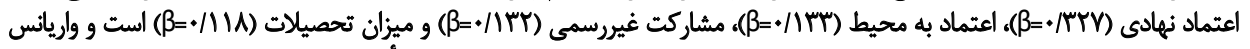

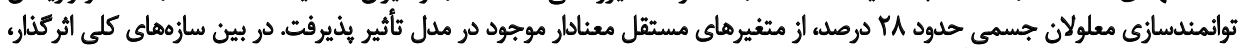

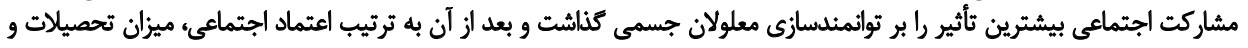
فعاليتهاى ورزشى قرار داشتيند.

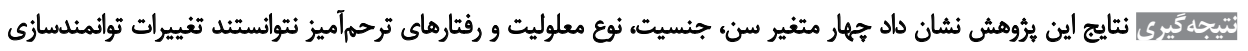

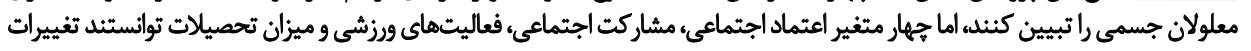

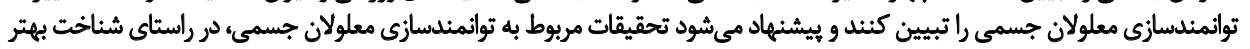

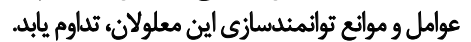

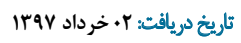

تاريخ هذيرش: 19 آبان

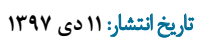




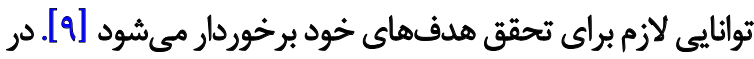

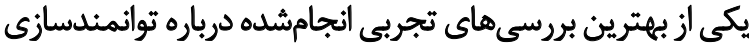

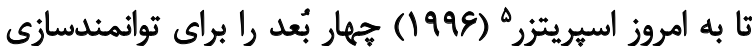

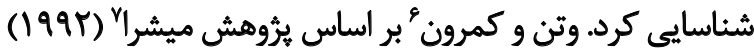

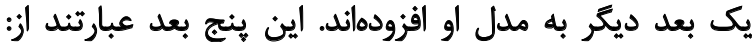

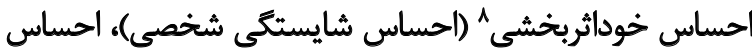

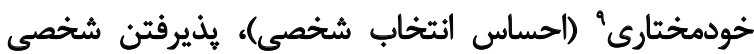

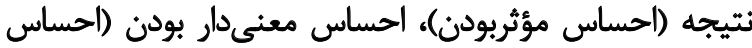

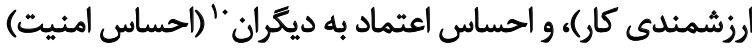

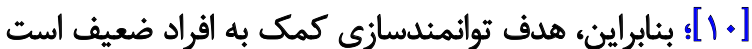

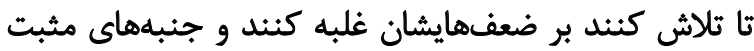
زئدكىشان را بهببود ببخشند و استعدادهاي خود رابن راش شكوفا كنند.

امروزه، ما با ديدكاه اجتماعي جديد توسعهيافته حقوق بشر

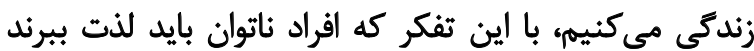

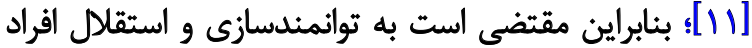

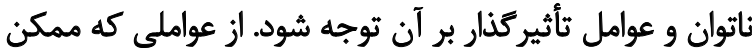

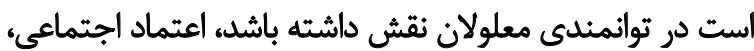

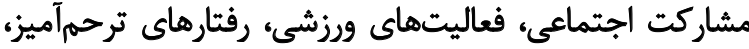

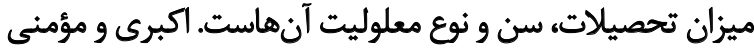

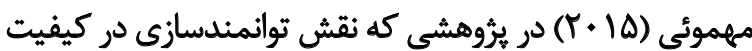

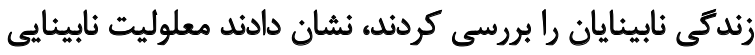

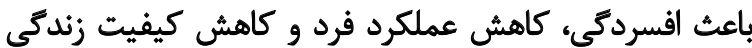

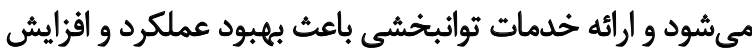

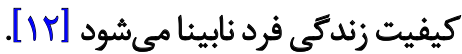

احمدى و همكاران (Y. Y (Y) در يُوهشى نشان دادند بين

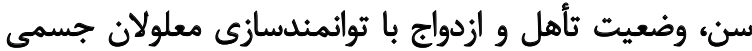

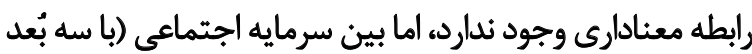

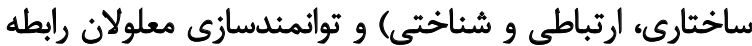

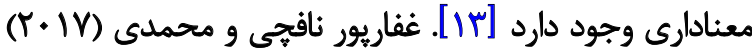

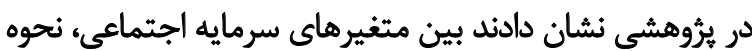

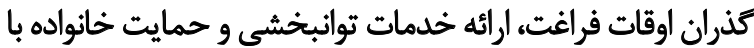

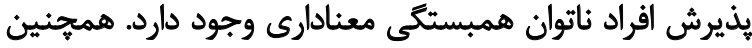

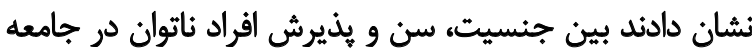

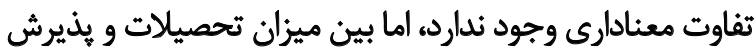

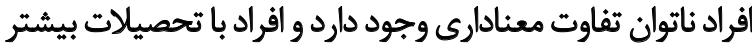

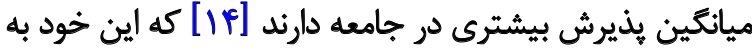
توانمندى آنها مي افززايد. خسروى و همكاران (10 (r) در يُروهشى نشان دادئد

5. Spreitzer

6. Veton \& Cameron

7. Mishra

8. Self-efficacy

9. Self-determination

10. Trust in other
مقلمه

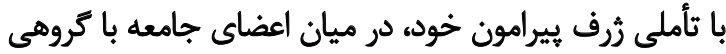
برخورد مى كنيم كه دهار معلوليت هستئند

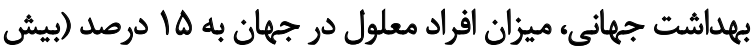

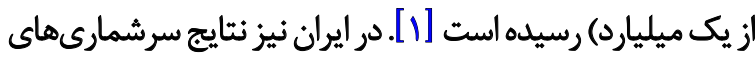

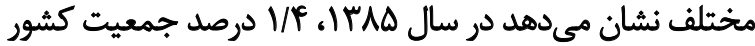

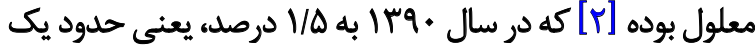

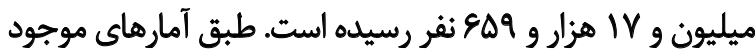

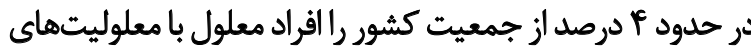

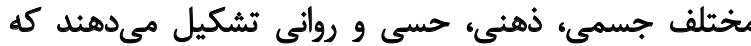

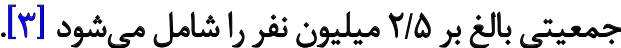

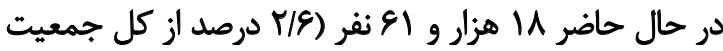

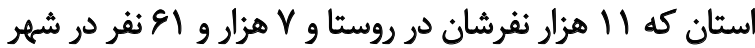

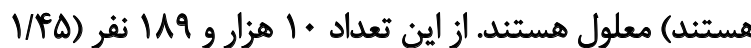

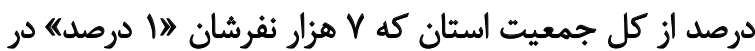

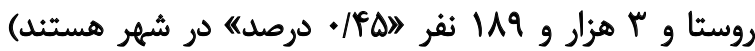

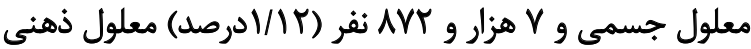

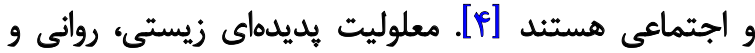

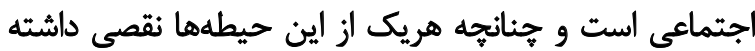

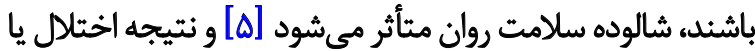

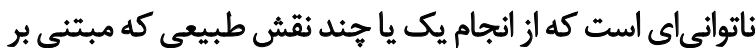

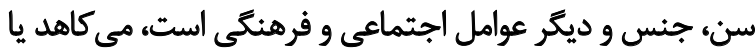

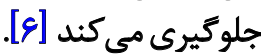

از ديدكاه توانبخشى معلوليتها به سه دسته ذهنى و روانى،

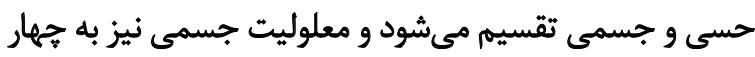

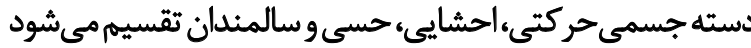

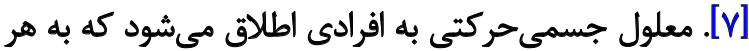

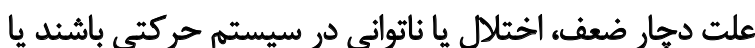

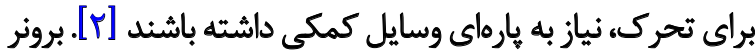

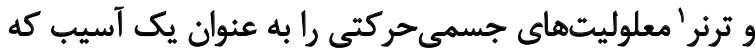

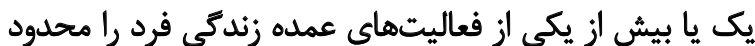

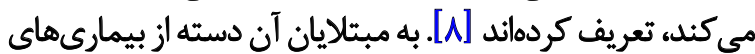

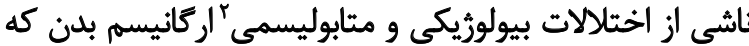

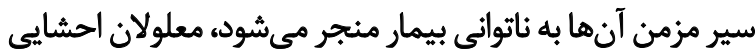

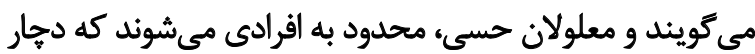

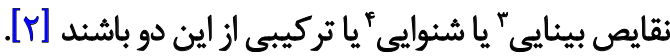
توانمندسازى فرايندى است كه جامعه از راه آن، از نيازها و و

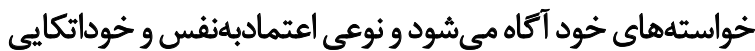
را براى برطرفكردن آن نيازها به دست مى آورد و بر اساس آن آن ازئ

\footnotetext{
1. Brown \& Turner

2. Biological and metabolic disorders

3. Visual impairment

4. Hearing impairment
} 
معلوليت و رابطه آنها با توانمندسازى معلولان جسمى راكه در بردي

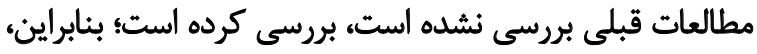

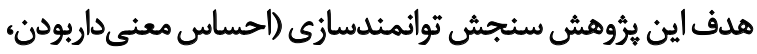

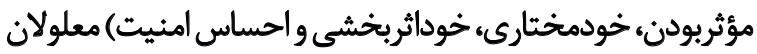

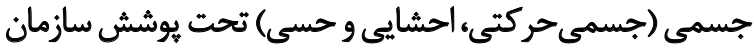

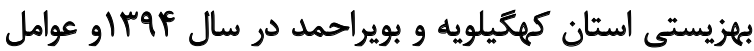
مرتبط با آن است.

\section{ورش بروسى}

در اين يرؤهش، روش تحقيق بيمايشى و از نوع مقطعى تحليلى برائي

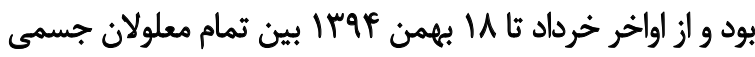

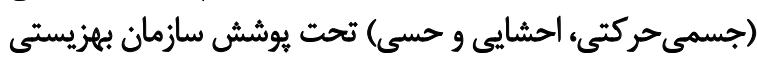

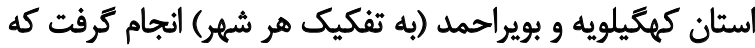

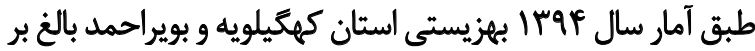

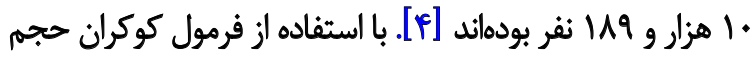

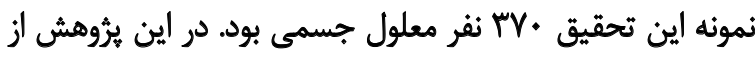
روش نمونهيرى تصادفى نسبتى در بين 1 شهر استان كهيخيلويه و

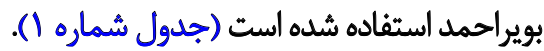

ابزار جمعآورى اطلاعات، برسشنامه محققىساخته با f أسؤال

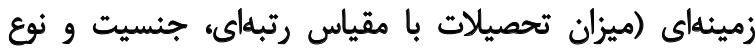

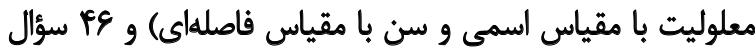

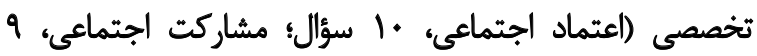

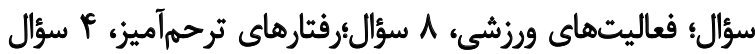

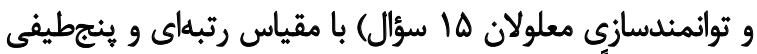

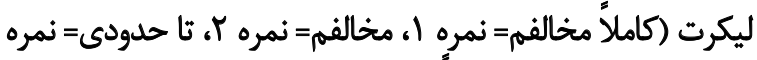

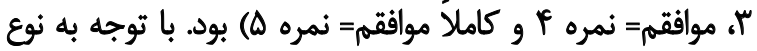

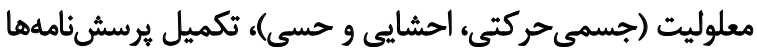

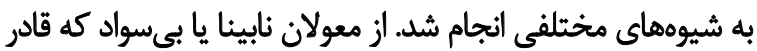

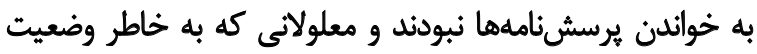

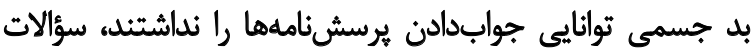

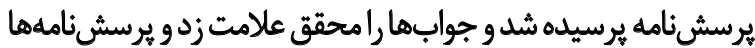

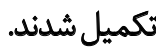

براي ديكر معلولان جسمى از جمله معلولان ناشنوا، قطع عضو،

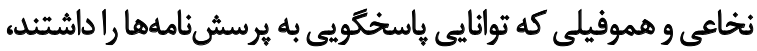

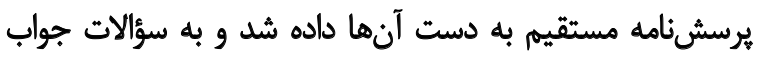

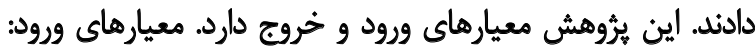

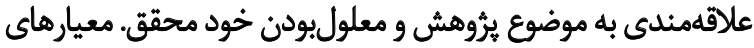
خروج: معلولان شهرهاى استان كه در زمئ زمينهاى (ادامه تحصيل،

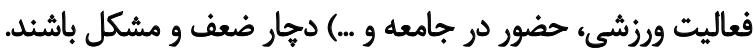

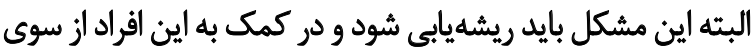

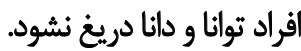

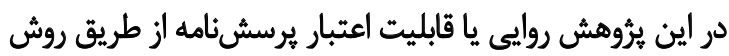

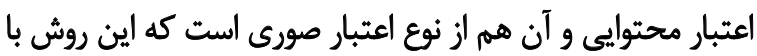

بين خردهمقياسهاى حمايت اجتماعى (حمايت اجتماعى

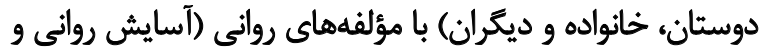

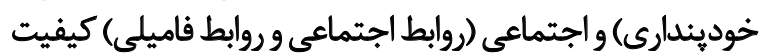

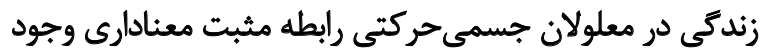

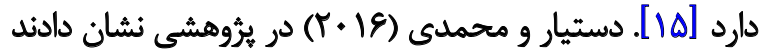

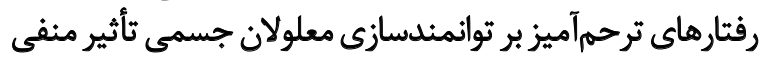

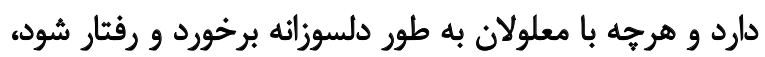

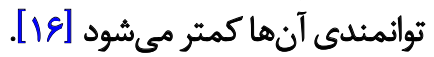

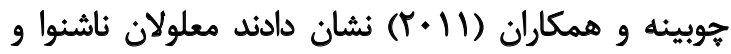

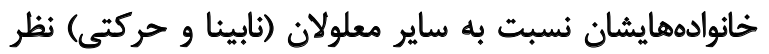

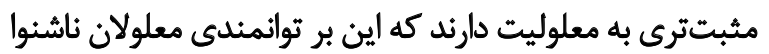

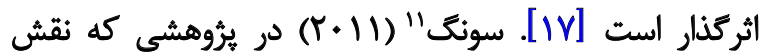

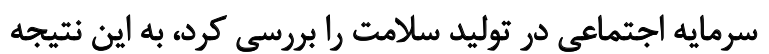

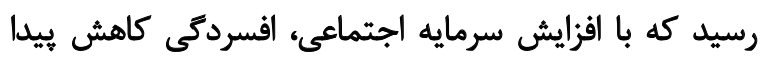

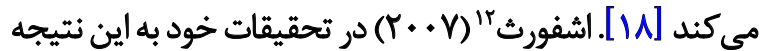

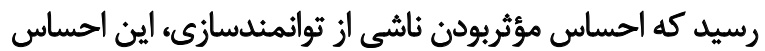

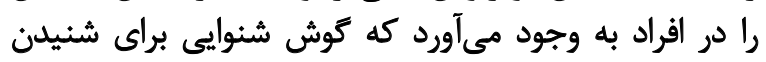

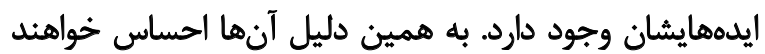

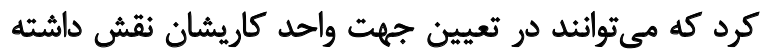

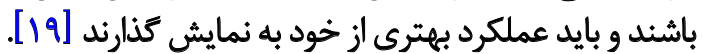

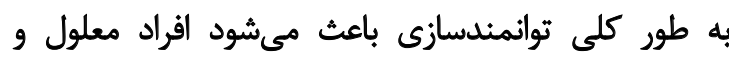

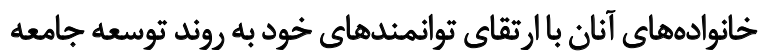

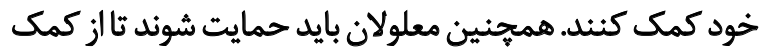

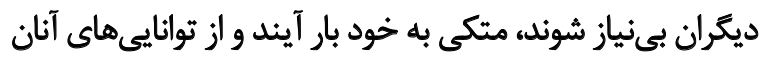

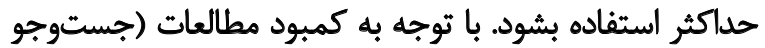

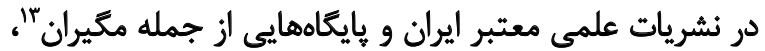

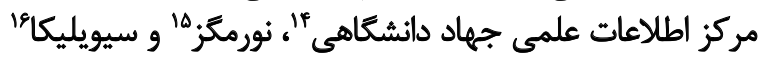

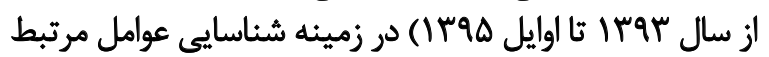

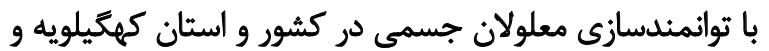

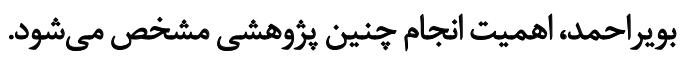

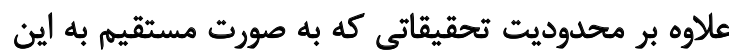

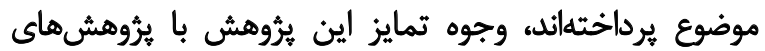

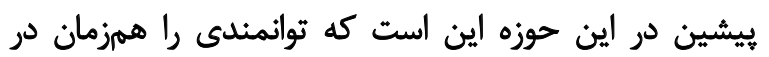

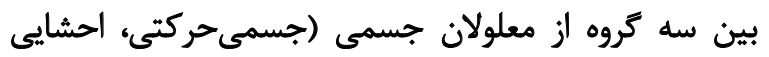

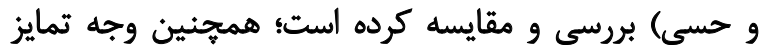

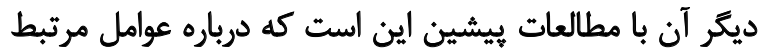

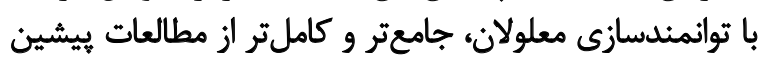

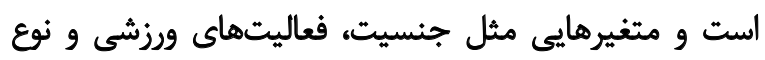


جدول ا. تعداد نمونه آمارى به تفكيك هر شهر

\begin{tabular}{|c|c|c|}
\hline تعداد (نموثه آمارى) & تعداد (جامعه آمارىى) & شهر \\
\hline$n$ & $r+t g$ & دهلشت \\
\hline AY & זru & ياسوج \\
\hline re & 1.08 & سىسخت \\
\hline$M$ & MFip & كَجساران \\
\hline IV & 181 & لثنده \\
\hline 19 & ArE & باثت \\
\hline TV & $n r$ & جرام \\
\hline Tr & 8.1 & بهمثى \\
\hline$r v$ & 1.119 & جمع \\
\hline
\end{tabular}

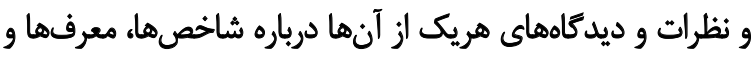

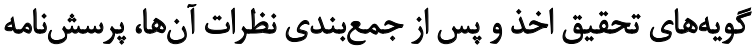

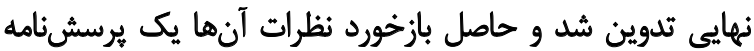

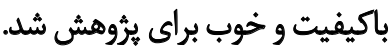

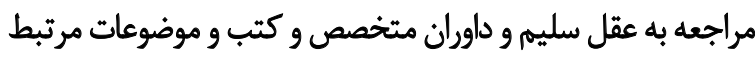

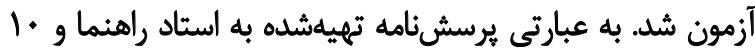

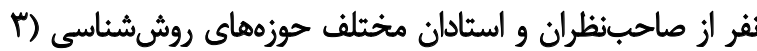

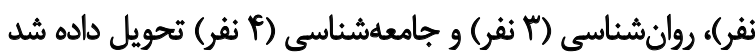

جدول r. معرفى دقيق متغيرهاى تحقيق با ابعاد آنها ( كزارش تعداد كويهها، مقياس، طيف و ميزان بايايى آنها).

\begin{tabular}{|c|c|c|c|}
\hline مقياس وطيف & هياياييى & تويدهاد & متغيرها \\
\hline \multirow{3}{*}{ بنبطوطيفى } & 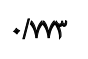 & 9 & مشاركت اجتماعى \\
\hline & $\cdot N+1$ & i & مشاركت رسمى (مشاركت در تيههايى ورزشى، انجمن اوليا، اتحاديهها، مشاركت در امور مذهبى و غيره) \\
\hline & . NSA & $\Delta$ & مشاركت غيررسمى (مشاركت در تفريحات دستهجمعى، مشاركت در سطح محله و غيره) \\
\hline \multirow{4}{*}{ بنتجطيفى } & $\cdot M I$ & 1. & اعتماد اجتماعى \\
\hline & +NAS & f & اعتماد بين شخصى (اعتماد به خانواده، دوستان، همكلاسى ها و استادان) \\
\hline & .1999 & r & اعتماد به محيط (تعميمياقته) (العتماد كلى به جامعه، راستكويع و صلاقت) \\
\hline &. $\mathrm{N} \cdot$. & r & اعتماد نهادى (اعتمادى كه افراد معلول به نهادها الارند) \\
\hline \multirow{3}{*}{ ينجطيفيفى رتيلي } & •/ASE & $\wedge$ & فعاليتهاى ورزشى \\
\hline & . Mrr & 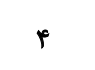 & ارتثاى سلامت روانى (كاهش (افسردكى، اضطراب، اختلالات روانتنى، وسواس و ووانيريشى) \\
\hline & . MTA & $\varphi$ & ارتقاى سلامت جسمانى (الستفاده الز احساسات باقىمائده و تقويت قواى جسمانى) \\
\hline ينجطيفيفى & $. / 9 .$. & 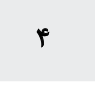 & رفتار هاى ترحماميز (رفتارهايى ترحهما ميز دوستان، خانواده، اقوامو و مستولان جامعه) \\
\hline \multirow{6}{*}{ ينتطيطيفي } & I/APP & 10 & 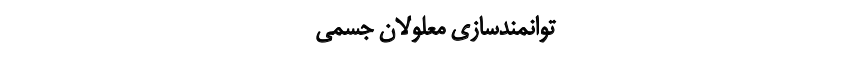 \\
\hline & זים & r & الحساس معنى الربودن (الحساس ارزنشمنى كار) \\
\hline &.$M 9$ & r & الحساس مؤربرون (بذيرفتن شخصى ثتيجه) \\
\hline &.$/ m 9$ & r & احساس خولمختارى (الحساس انتخاب شخصى) \\
\hline & $.18 \cdot 4$ & r & احساس خوداثربخشى (احساس شايستى شخصى) \\
\hline &.$/ 919$ & r & احساس امنيت (احساس اعتماد به ديكران) \\
\hline
\end{tabular}




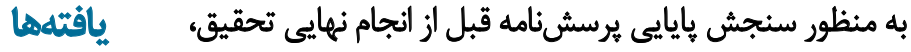

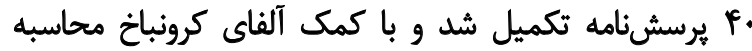

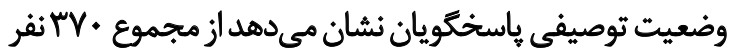

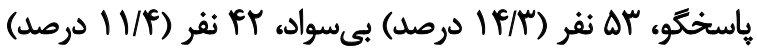

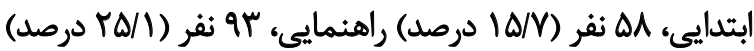

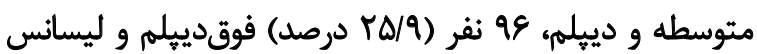

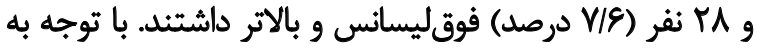

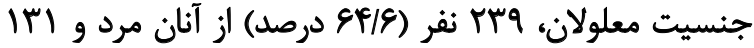

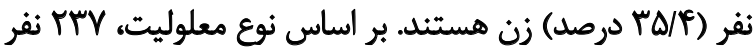

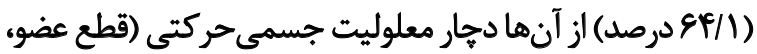

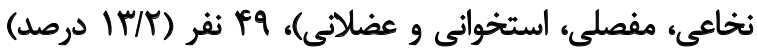

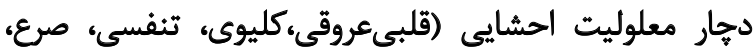

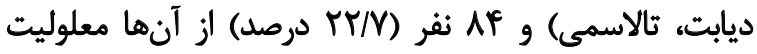

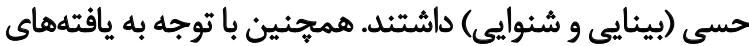

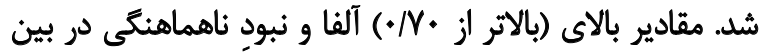

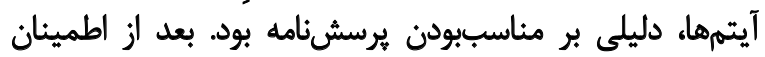

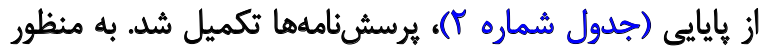

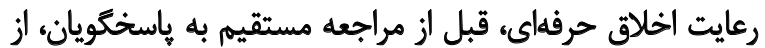

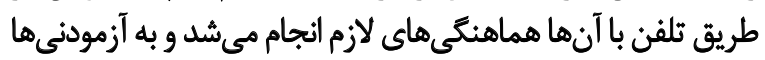

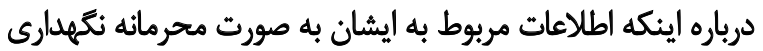

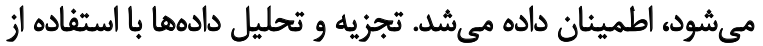

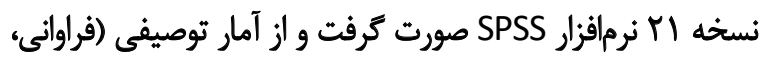

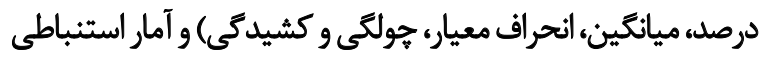

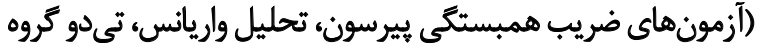
مستقل، ركرسيون جندمتغيره و تحليل مسير) استفاده شد. تحلي

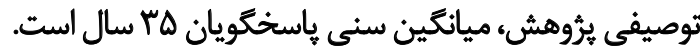

جدول r.خلاصه وضعيت آمار توصيفى متغيرهاى تحقيق و بررسى نرمال بودن آنها

\begin{tabular}{|c|c|c|c|c|c|c|c|}
\hline كشيد5ى & هولكى & حداكثر & حداقل & دامنه & انحراف معيار & مياتكين & متغيرها \\
\hline.$/ M F$ &.$- / T H$ & Po & 9 & $r e$ & $s / \pi 1$ & $\pi / \div 9$ & مشاركت اجتماعى \\
\hline IMV & $-+/ T A Y$ & r. & $r$ & 18 & $r / \cdot v e$ & $19 / \% 9$ & مشاركت رسمى \\
\hline$-* 1 \cdot 1$ &.$- / T T E$ & ro & $\Delta$ & r. & $P / T \cdot V$ & $I V / A$. & مشاركت غيررسمى \\
\hline I/TAV & $-. / 9+r$ & Q. & ro & To & $p(p)$. & $H T / .1$ & العتماد اجتماعى \\
\hline.$M W$ & - FAq & r. & $r$ & 18 & W/TA & WIT & العتماد بين شخصى \\
\hline.$- / 114$ &.$- / A M F$ & 10 & 8 & 9 & INAV & $I r / V \Delta$ & اعتماد به محيط \\
\hline.$- / .14$ &.$- / 8 n$ & 10 & $r$ & ir & $r / 9 .$. & $11 / / r$ & اعتماد نهادى \\
\hline I/TVE & $-+/ 941$ & f. & II & rV & $F / F M$ & $r=/ v q$ & فعاليتهاى ورزشى \\
\hline.$/ 419$ & $-\cdot / 1 \cdot r$ & r. & $\Delta$ & 10 & r/sr) & $18 / 98$ & ارتقاى سلامت جسمائى \\
\hline$V / P+r$ & $-1 / .98$ & r. & $\wedge$ & ir & $t / n+t$ & IV/AY & ارتقاى سلامت روانى \\
\hline.$- / 118$ & $V \cdot 1 \mathrm{u}$ & r. & r & 18 & r/MV & NMA & رفُقتارهائ ترحمأميز \\
\hline $1 / 4 a s$ &.$- / 119$ & vo & rV & PA & V/a1A & ET/. & توانمندسازى مملولان جسمى \\
\hline - /ATE & $-\cdot 19 \cdot 7$ & 10 & $r$ & ir & T/TAS & $1 r / e q$ & احساس معنى دار بودن \\
\hline . NET & $-\infty / 4 r$ & 10 & $r$ & ir & (4) & $11 / \epsilon_{A}$ & الحساس هؤثر بودن \\
\hline V.H & $-1 / 1 / f$ & 10 & $r$ & ir & V/q4e & $\mid r / .9$ & احساس خودمختارى \\
\hline $1 / 29$. & $-\oplus / 9 \Delta \mathrm{Y}$ & 10 & $\checkmark$ & $\wedge$ & VET. & Ir/AV & احساس خوداثربخشى \\
\hline.$- / T \Delta 1$ & $-\bullet / I V$ & 10 & $\checkmark$ & $\wedge$ & $\mid(N D \mid$ & $I r / M$ & احساس امنيت \\
\hline
\end{tabular}


جدول ؟.نتايج آزمون تحليل واريانس تواثمندسازى معلولان جسمى و يتايج آزمون تى مستقل توانمثدسازى معلولان جسمى

\begin{tabular}{|c|c|c|c|c|c|c|}
\hline 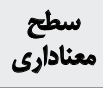 & 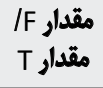 & درجه ازادى & ميانكين النحراف معيار & تعداد & شاخص أمارى & مثفير \\
\hline \multirow{7}{*}{$\%$} & \multirow{7}{*}{ SMM } & \multirow{7}{*}{ 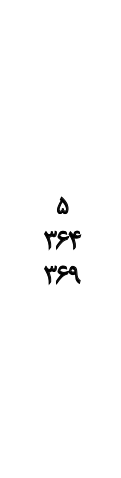 } & $\Delta V / F \backslash \pm 11 / F A$ & $\Delta r$ & ليىسواد & \multirow{7}{*}{ ميزان تحصيلات } \\
\hline & & & $g r / P Y \pm V / / q$ & ir & إبتدايع & \\
\hline & & & S./qYIF/FD & $\Delta \wedge$ & ر اهنمايى & \\
\hline & & & $S T / P Y \pm F / N$. & १" & متوسطه ودييلم & \\
\hline & & & $g T N \pm \& / 9 T$ & $q$ & فوقدييله و ليسانس & \\
\hline & & & $98 / . V \pm 9 / .4$ & rA & فوقليسانس و بالاتر & \\
\hline & & & $g / 1 \cdot \pm V / 91$ & $r$. & جمع لج & \\
\hline \multirow{4}{*}{.$/ 1 n$} & \multirow{4}{*}{ INAD } & \multirow{4}{*}{$\begin{array}{c}r \\
r y q \\
r \& 9\end{array}$} & ST/QADNIT & $\pi r$ & جسمى حركى (قطع عضو، نخاعى، مفصلى، استخوانى & \multirow{4}{*}{ نوع معلوليت } \\
\hline & & & $9 \cdot / \pi T \pm / T$. & pq & الحشايع (قليىعروقى،كليوى، تنفس، صرع، ديابت، & \\
\hline & & & SIWENIT & Af & حسى (بينايع و شنوايى) & \\
\hline & & & $9 \times / 1 \cdot \pm V / 91$ & $\mathrm{rv}$. & جمع & \\
\hline \multirow{2}{*}{. NAS } & \multirow{2}{*}{.$/ 11$} & \multirow{2}{*}{ 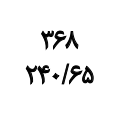 } & $g Y / . . \pm V / \Delta \Delta$ & Trq & مرد & \multirow{2}{*}{ جنسيت } \\
\hline & & & ST/TAINAS & וm & زن ن من & \\
\hline
\end{tabular}

توانبخنتى

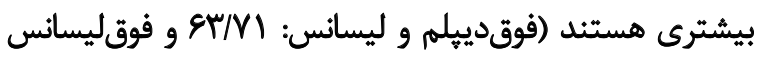

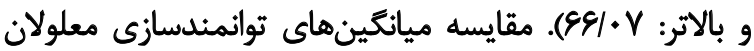

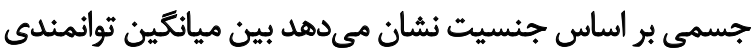

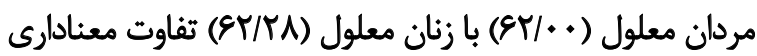

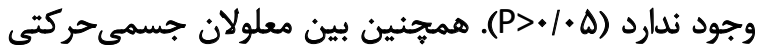

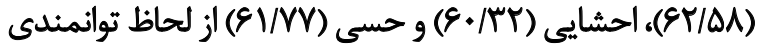

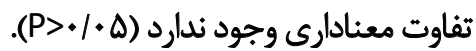

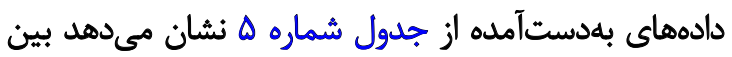

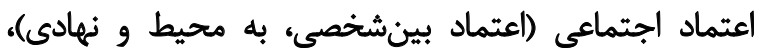

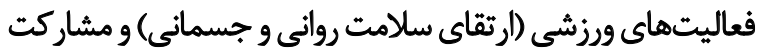

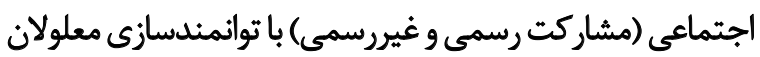

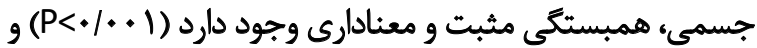

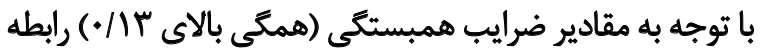

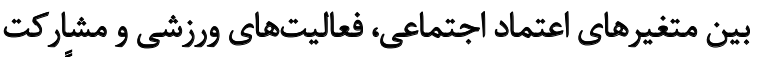

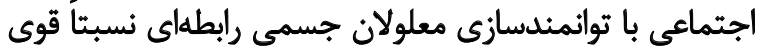

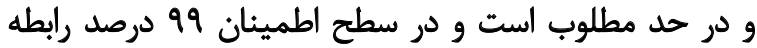

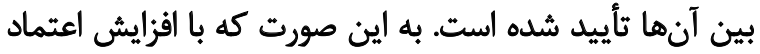

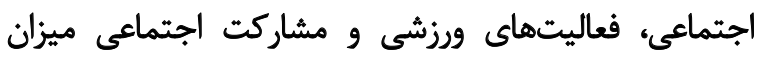
توانمئدى معلولان هم افزايش يافته است، اما بين رفتارهاى اجنماعي

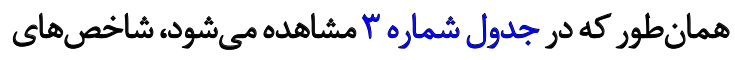

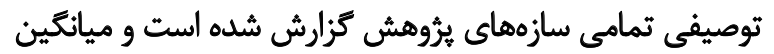

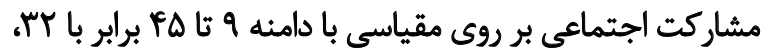

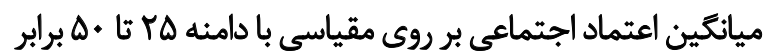

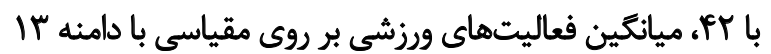

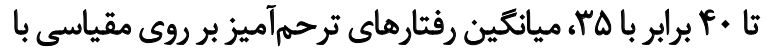

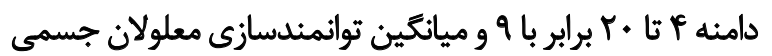

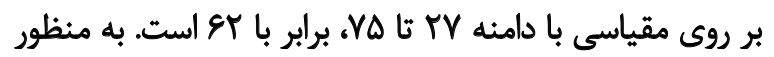

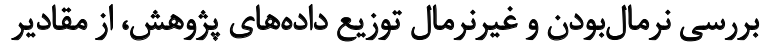

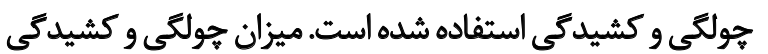

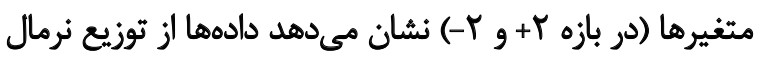

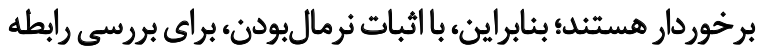

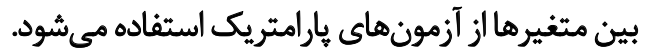

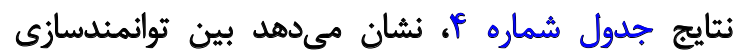

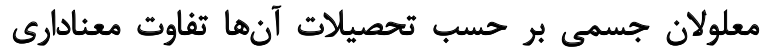

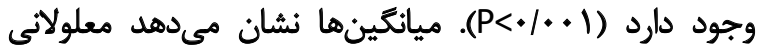

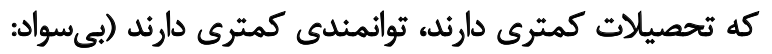
AV/FI ابتدايى: ST/FV

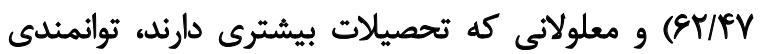


جدول ه. نتايج آزمون ضريب همبستكى هيرسون

\begin{tabular}{|c|c|c|c|c|c|c|}
\hline معلولان جسميمى تواندى & احساس امنيت & خهوداثربحشي احسي & 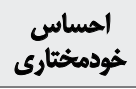 & مؤثريودن & معني احساس & رابطله بين تمامى مثثيرها \\
\hline.$/ 41 \mathrm{~N}^{* *}$ & - Mraren &.$/ M M^{* *}$ &.$/ \pi V * *$ &.$/ M T^{* *}$ & . & $\mathrm{R}$ \\
\hline $1 \ldots$ & 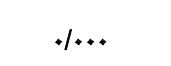 & $\%$ & .10. & 10 & 10. & اعثماد اجتماعى \\
\hline.$/ 1 r a *$ &.$/ 1 T^{*}$ &. $\mid(n)^{*}$ &.$/ 100^{* *}$ & $\%$. V8 & $\% \Delta r$ & $\mathrm{R}$ \\
\hline $.1 .+9$ & $.1 \cdot 11$ & $+\infty 1$ & $\%$ & / / & $=\pi+\Delta$ & اعتماد بيين سحصى \\
\hline.$/ 189 *$ & - MEN" &.$/ T M^{* *}$ & .1 .91 & $\cdot N+1$ & $.1 \cdot \pi$ & b- \\
\hline $.1+\infty 1$ & 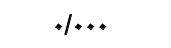 & $+\cdots$ & $.1 \times A 1$ & 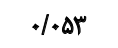 & - Mta. & ons \\
\hline . $/ F T \Lambda^{* *}$ & $. / r q+\cdots$ & - MArew &.$/ r u^{* *}$ &.$/ T V^{* *}$ & ./FTq"* & $\mathrm{R}$ \\
\hline$\%$ & $+\ldots$ & 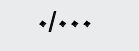 & $\%$ & $\%$ & $\%$ & 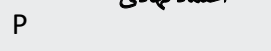 \\
\hline$+/ f+f=$ &.$M I D^{* *}$ & . Merat &.$/ 4 a^{* *}$ & $. / T H=$ & $\cdot / \pi+*$ & $\mathrm{R}$ \\
\hline$+1+\infty$ & $+\%+$ & $+1+\infty$ & 100 & $100+$ & $100+$ & هشار كت اجتماعى \\
\hline$+/ T V q^{* *}$ & - Mere & $+R I D^{* *}$ & $+/ 1 \gamma_{*} * *$ &.$/ T M * *$ & $+/ 198 *$ & $\mathrm{R}$ \\
\hline$+\infty+\infty$ & $+\%$ & $+1+*+$ & .10 .1 & $\%$ & $10+$ & هشاركت رسمى \\
\hline$+/ Y+Y=*$ & $+/ r q+\cdots$ & $+M H \lambda^{* *}$ & +/rAq** & -Mege* & . & $\mathrm{R}$ \\
\hline$*+\infty$ & $+\cdots$ & $+4+*$ & $\%$ & $.100+$ & $\%$ & هشاركت غيررسمى \\
\hline$+/ T+r+m$ & ./19pen & $+/ \pi r+*$ & o/Imen & $\cdot / M_{*} * *$ & $.1+41$ & $\mathrm{R}$ \\
\hline$+1+\infty$ & $+10+$ & $+1+*$ & .101 & 10. & | & encos \\
\hline$+/ M \Delta^{* *}$ & $* / A^{*} * *$ & $+/ \pi 4 \Delta^{* *}$ & $\cdot N \cdot r^{*}$ & $-/ 1 \Delta A^{* *}$ & $1 . \pi r$ & $\mathrm{R}$ \\
\hline o $\ldots$ & $+1 *+1$ & $+\ldots$ & $1.19 q$ & .10 .5 & $.18 \Delta \mathrm{A}$ & 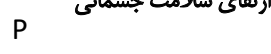 \\
\hline$+/ r+r^{* *}$ &.$/ 194 * *$ & $+/ T M$ & . $/ 1 \Delta q^{* *}$ &.$/ \mathrm{M}^{* *}$ & $.1 . \Delta q$ & $\mathrm{R}$ \\
\hline 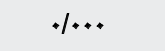 & $* \ldots$ & $+\ldots$ & 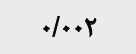 & $1 \ldots$ &. $\mid K 81$ & (19) \\
\hline$-+1+4 f$ & $+|+4|$ & $-4 / 19$ & $-+/ N \omega^{* *}$ & $-+\mid+T_{1}$ & $-+1+\pi \Delta$ & $\mathrm{R}$ \\
\hline.$/ 798$ & TH & . $/ Y I r$ & .101 & $\cdot|F A|$ &.$/ 4 q 1$ & $P$ \\
\hline.$/+4 T$ &.$/ .11$ & $1+\Delta$ & $.1 . \Delta A$ & 1.44 & .1011 & $\mathrm{R}$ \\
\hline.$/ 411$ & - /ATA & D. & . TEY & . $/ 2$ & - DT & $\mathrm{P}$ \\
\hline
\end{tabular}

تأثير مىيذيرد. به منظور تعيين تأثيرات مستقيم و غيرمستقيم

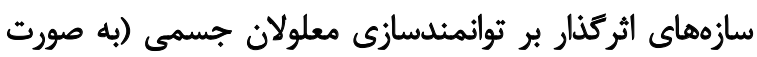
كلى) از تحليل مسير استفاده شده است (تصوير شماره ()). بحث

هدف اصلى توانمندسازى، افزايش قدرت و توانايى افراد معلول

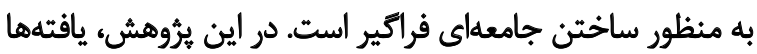

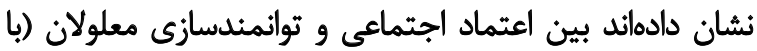

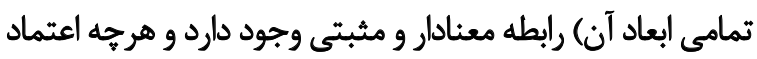
اجتماعى معلولان جسمى افزايش يابد، ميزان توانمندسازي آندار آنها
ترحممآميز و سن با توانمندسازى معلولان جسمى رابطه معنادارى

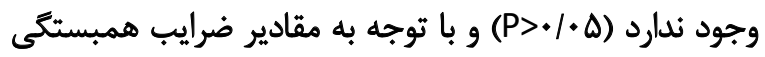

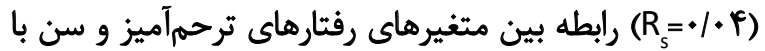

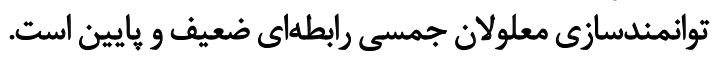

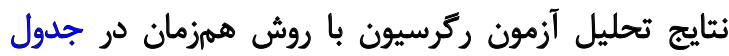

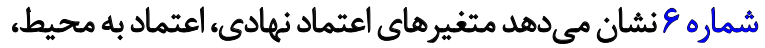

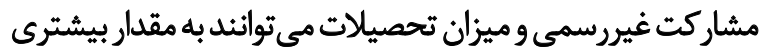

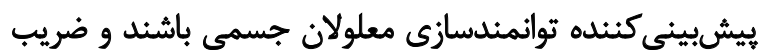
تعيين (RA

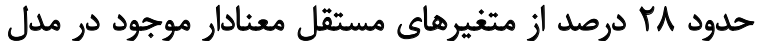


جدول و. نتايج تحليل ركرسيون همزمان (ارتباط بين توائمندسازى معلولان جسمى با متغيرهاي مستقل)

\begin{tabular}{|c|c|c|c|c|c|c|c|c|c|}
\hline معنادارى & آزادى & تنظيهزشوره R R & تريين & ضمبسيتّى & مقدار F & معنادارى & مقدار t & ضريب بتا & شاخص آمارى \\
\hline \multirow{9}{*}{$\% \ldots$} & & \multirow{9}{*}{. TEA } & \multirow{9}{*}{$. / T A \mid$} & \multirow{9}{*}{. $/ \Delta H^{\circ}$} & \multirow{9}{*}{ IVIETA } & .1 .10 & $T /$ raf &.$/ 11 \mathrm{~A}$ & ميزان تحصيلات \\
\hline & & & & & &.$/ 190$ & . & $\% \mathrm{~V}$ & اعتماد بينشخصى \\
\hline & $\wedge$ & & & & &.$/ .14$ & $t / F e t$ & T & اعتماد به محيط \\
\hline & & & & & & $\%$ & $\Delta / 91 f$ &.$/ T H V$ & اعثماد نهادى \\
\hline & mel & & & & & & & & \\
\hline & & & & & & $\cdot / 8+\Delta$ & $+/ \Delta 1 \Lambda$ & $\%$ & مشاركت رسمى \\
\hline & req & & & & &.$/+r V$ & T/TIN &.$/ N T$ & مشاركت غيررسمى \\
\hline & & & & & & . IATA & . & .1 .01 & ارثقاى سلامت جسمانىى \\
\hline & & & & & &.$/ \pi V$ &.$/ 941$ & $.1 . V \Delta$ & ارتقائ سلامت روائى \\
\hline
\end{tabular}

توانبخننى

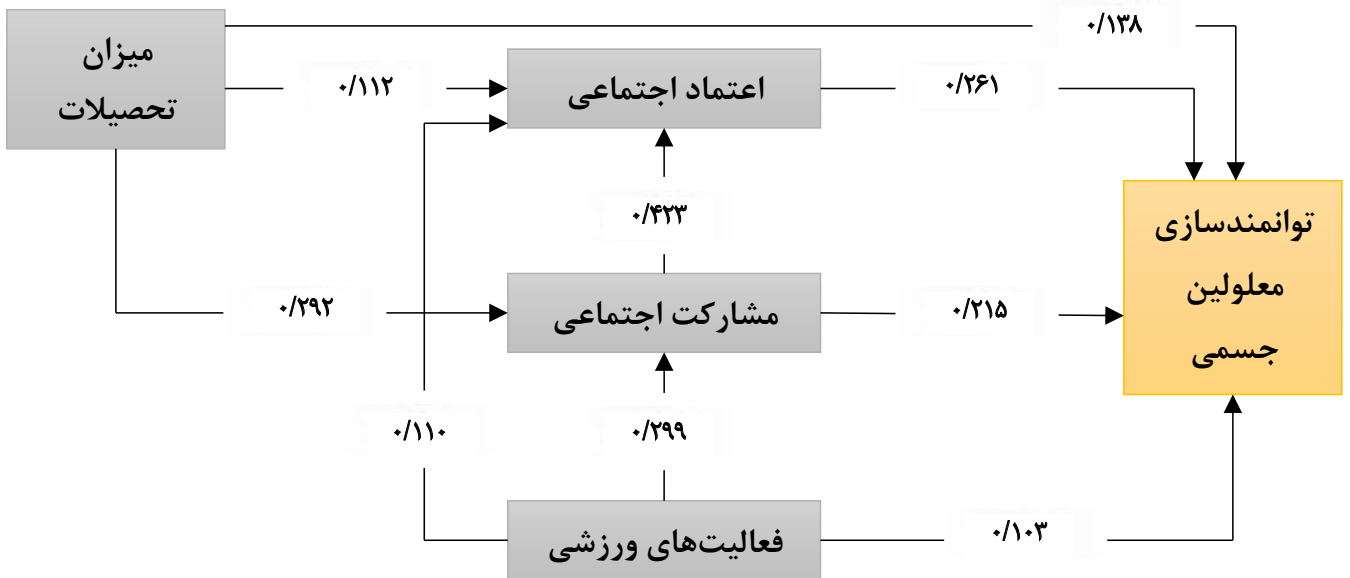

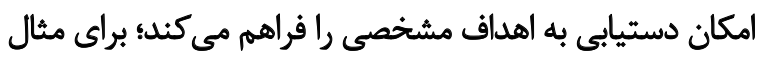

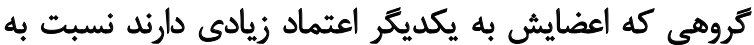

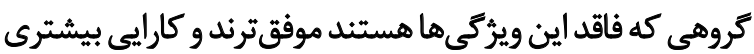

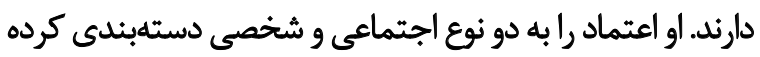

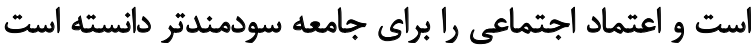

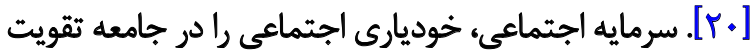

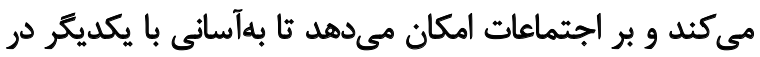

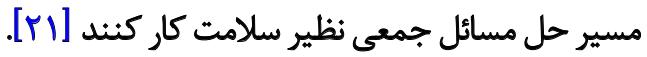
در فرضيه ديكرى از يرؤهش رابطه بين مشاركت اجتماعى إنى

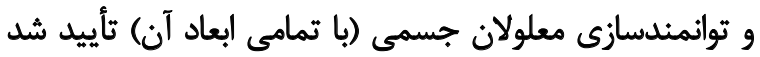

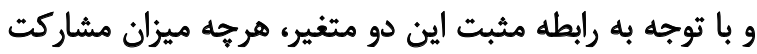

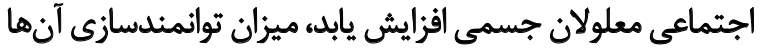

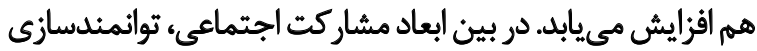

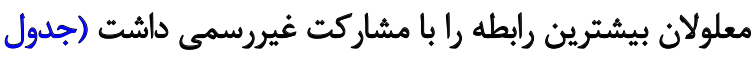

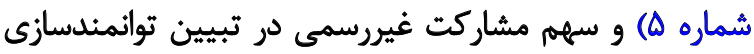

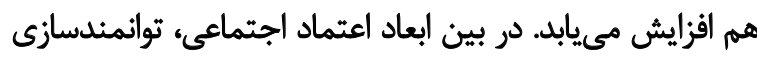

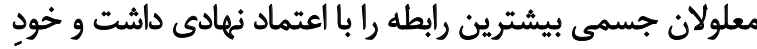

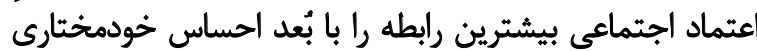
داشت كه يكى از ابعاد توايمندسازي است، (جدول شماره هـ). به طور كلى اعتماد اجتماعى قادر به تبيين عب درصد ازئ

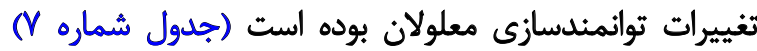

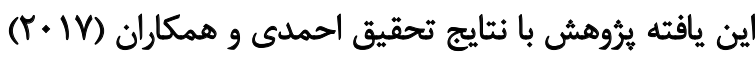

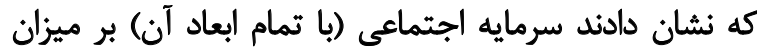

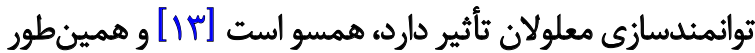

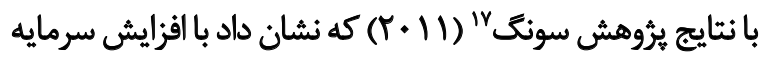

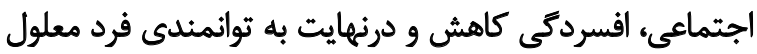

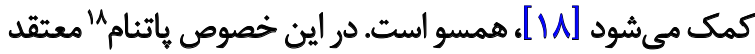

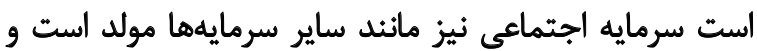

\section{Song}

18. Pantam 
جدول V.نتايج تحليل مسير

\begin{tabular}{|c|c|c|c|c|c|}
\hline \multirow{2}{*}{ تأثير كلى } & \multicolumn{3}{|c|}{ تأثير غيرمستقيم } & \multirow{2}{*}{ تأثير مسثقيم } & \multirow{2}{*}{ 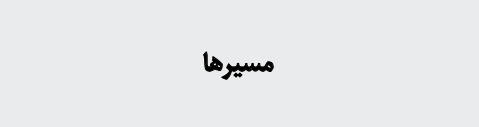 } \\
\hline & با سه مسير & با دو مسير & با يك مسير & & \\
\hline. $\mid r 81$ &.$/ N H$ & - & - &.$/ H A$ & تأثير ميزان تحصيلات بر تواتمندسازى معلولان جسمى \\
\hline 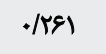 & - & - & - &.$|T E|$ & تأثير اعتماد اجتماعى بر تواتمنلسازيى هملولان جسمى \\
\hline ./ma & - & - &.$M$ & . MIQ & تأثير مشاركت اجتماعى بر توالمنلسازيى معلولان جسمى \\
\hline$\cdot \pi \cdot \Delta$ & $\cdot M \cdot r$ & - & - & $\cdot M \cdot r$ & تأثير فعاليتهاى ورزشى بر توانمندسازى معلولان جسمى \\
\hline
\end{tabular}

آنان كاركردهاى ورزش را شامل، كسب مهارتهاى اجتماعي،

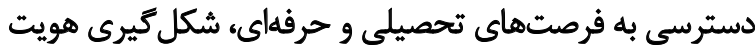

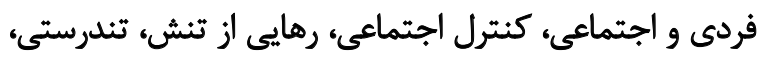

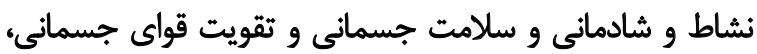

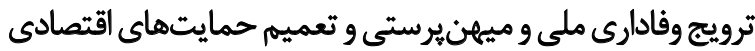

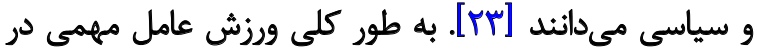

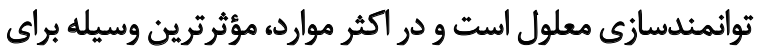

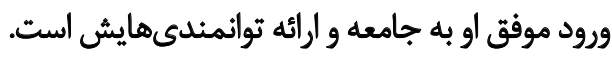
در اين يُوهش، همجينين يافتهها نشان دادند بين رفتارهاى

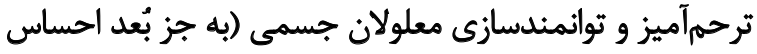

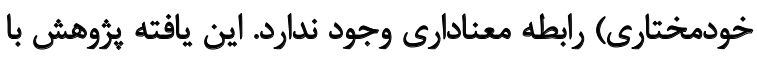

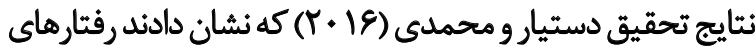

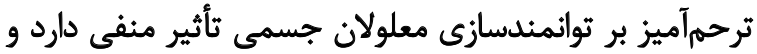

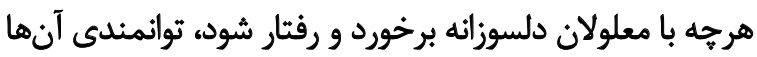

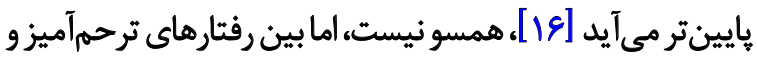

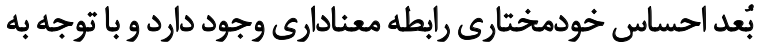

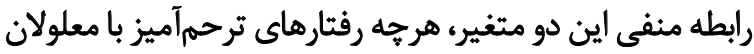

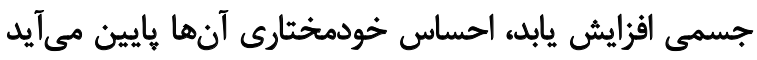

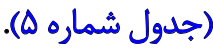

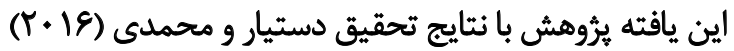

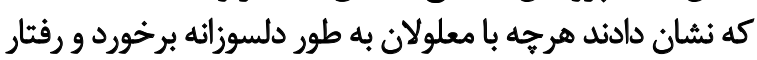

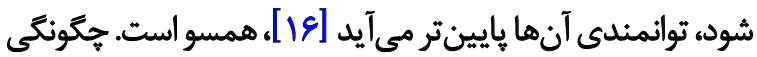

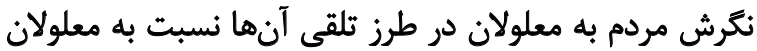

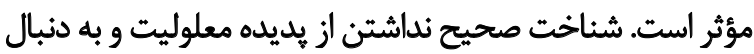

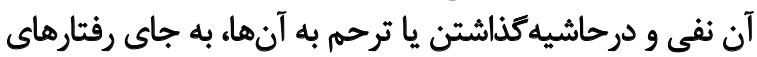

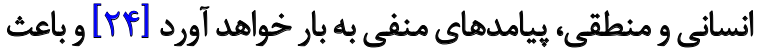
يايين آمدن توانمندى آنهامىشودي

در اين خصوص نظريه كنش مثقابل نمادى جرج هربرت مير ميد

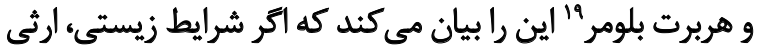

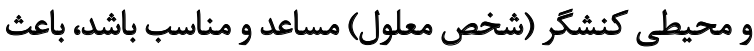

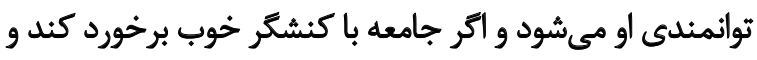

19. Herbert Mead \& Herbert Blumer

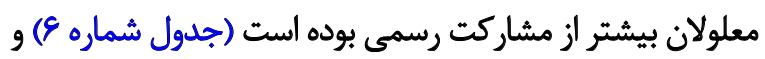

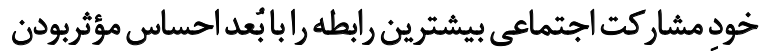

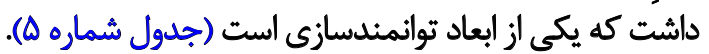

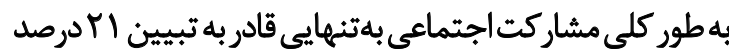

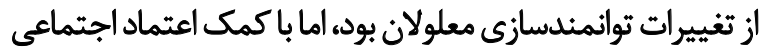

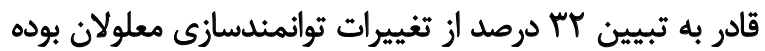

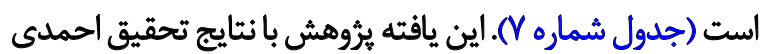

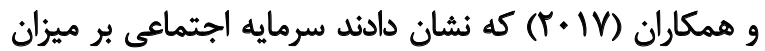

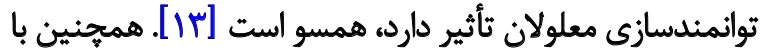

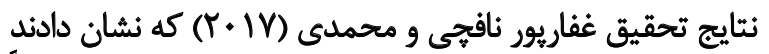

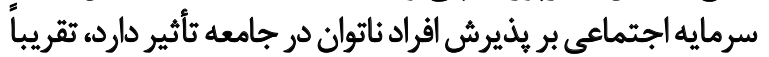

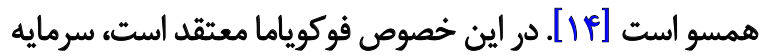

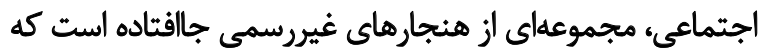

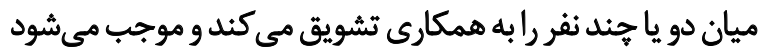

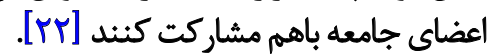

در فرضيه ديكرى از يثرهش رابطه بين فعاليتهاى ورزشى و

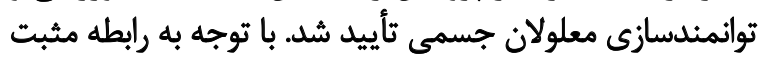

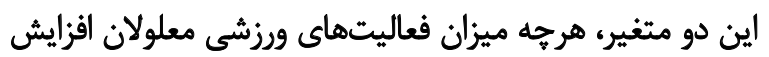

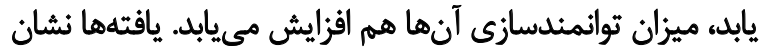

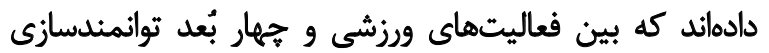

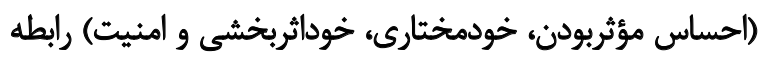

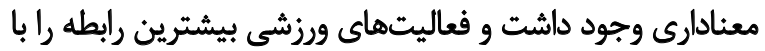

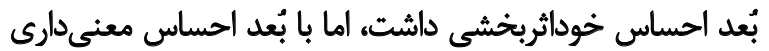

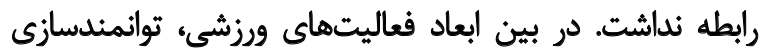

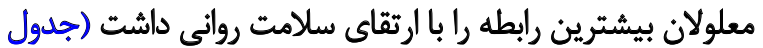

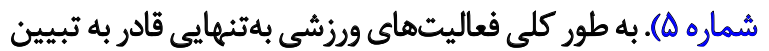

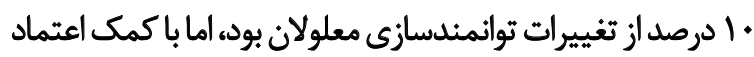

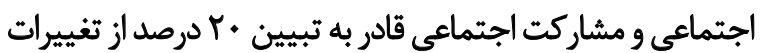
توانمندسازى معلولان بوده است (جدول شماره V).

در اين خصوص كاركردمرايان معتقدند، ورزش در سطح

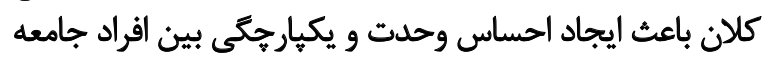
مىشود؛ جيزى كه در تحليل مسير يزؤهش نشان دادي داده شد. 
توانمندسازي معلولان و سن، تفاوت معنادارى وجود ندارد و سن

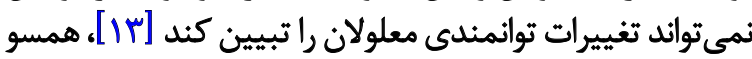

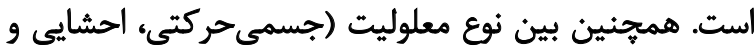

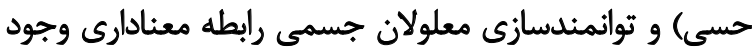
نداشت و توانمندى معلولان ربطى بولى به نوع معلوليت آنهان آنها ندارد

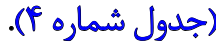

\section{نتيجلهَّيرى}

به طور كلى نتايج اين يُروهش نشان داد جهار متغير سن،

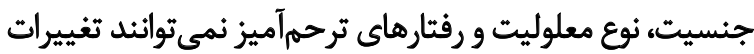

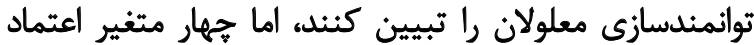

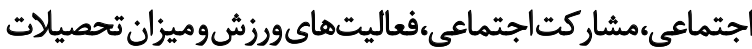

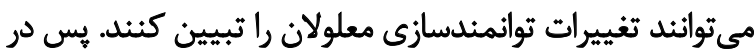

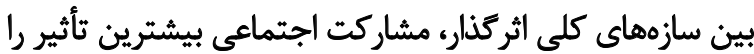

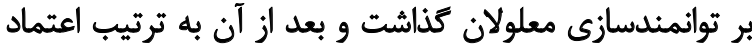

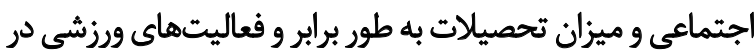

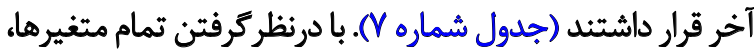

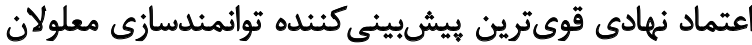

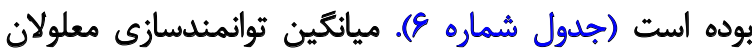

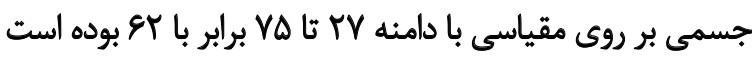

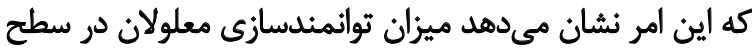

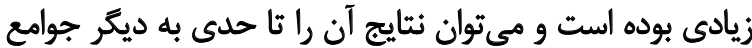

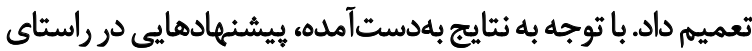
ارتقاى توانمندسازى معلولان جسمى ارائه مىشود.

دولتها و رسانههاى جمعى وظيفه دارند با فرهنغسازى در

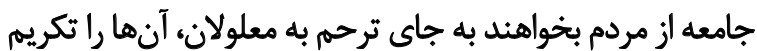

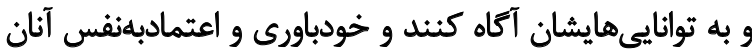

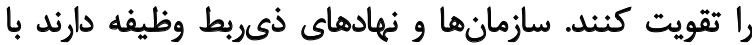

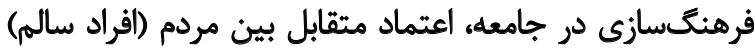

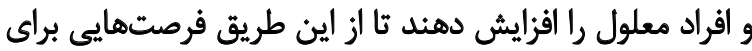

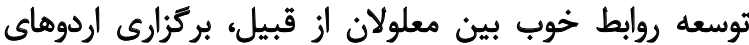

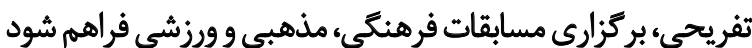

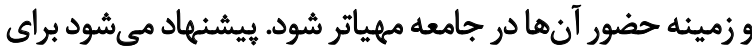

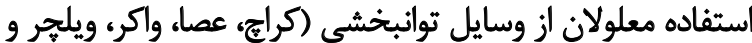
غيره) فرهنكسازي و شيوه استفاده از آنها آموزش دادي آدهان شود. همجنين محدوديتهاى تحصيلى و تبعيض بين دانشآموزان

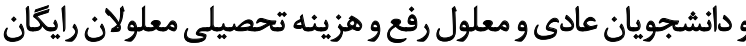

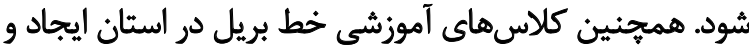

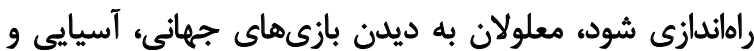

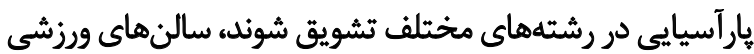

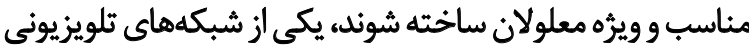

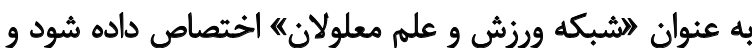
صحبتهاى معلولان موفق (در زميئه تحصيلى و ورزشي) به اختهاص
او رادر انزوا قرار ندهد و با او رفتار تحقيرآميز و ترحمآميز نداشته دئه

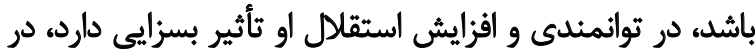

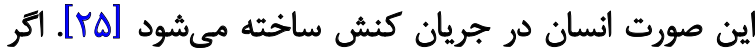

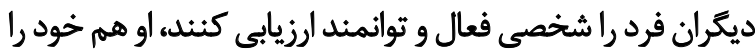

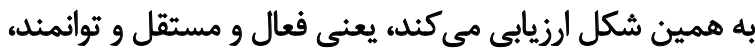

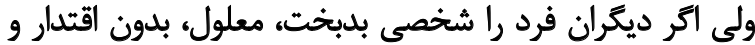

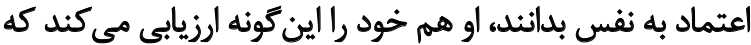

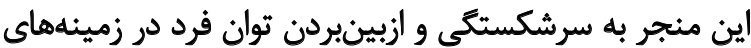

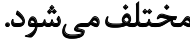

در فرضيه ديكرى از يثروهش رابطه بين ميزان تحصيلات و تواني

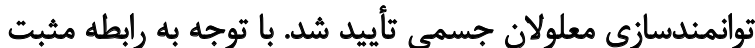

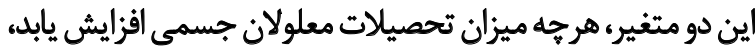

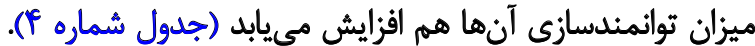

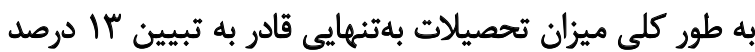

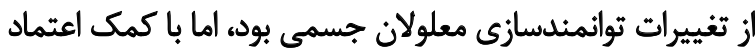

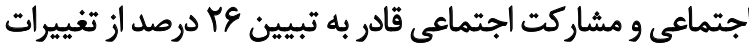

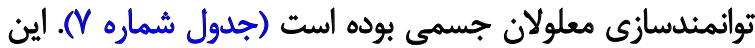

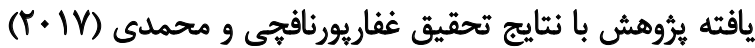

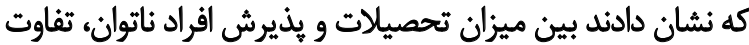

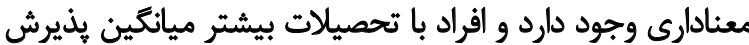

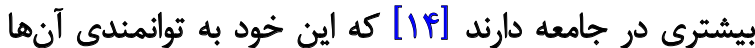
مى افزايد به نوعى همسو است.

كر اين خصوص نظريه شناخت اجتماعى بر احساس توانمندى

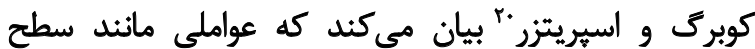

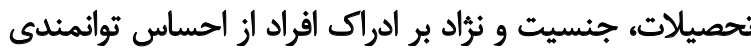

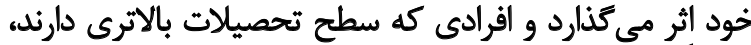

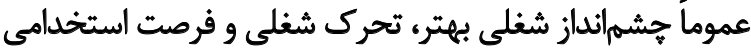

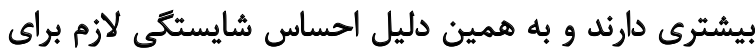

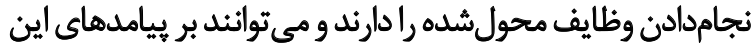

وظايف مؤثر واقع شوند و وظايف معنادارى داشته باشئد [عاند].

بين جنسيت و توانمندسازى معلولان جسمى رابطه معنادارى

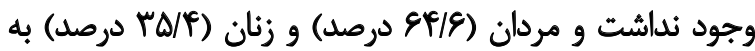

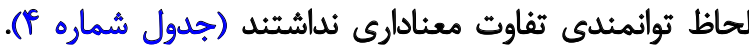

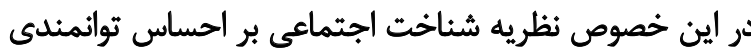

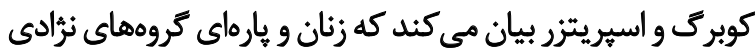

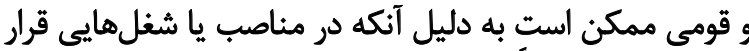

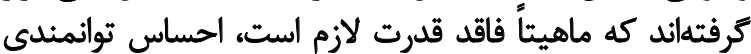

كمترى كنيد [TrV]

بين سن و توانمندسازى معلولان جسمى رابطه معنادارى وجود

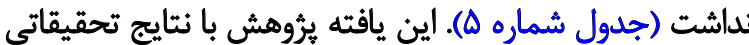

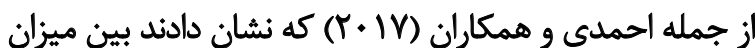

20. Spreitzer 


$$
\text { تشكر و قدردانى }
$$

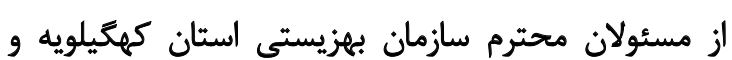

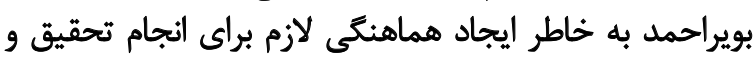

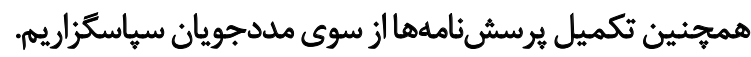

كوش ديگر معلولان برسد.

بيشنهاد مي شود در تحقيقات آتى تأثير سرمايه فرهنكي،

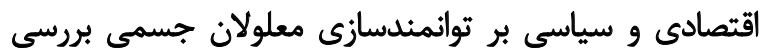

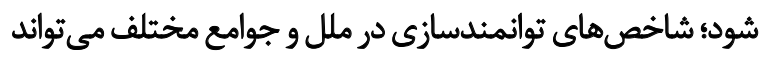

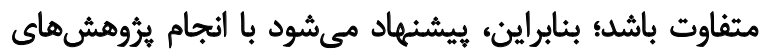

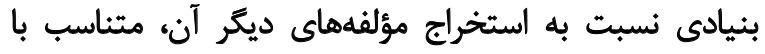

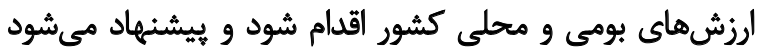

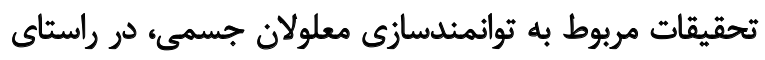

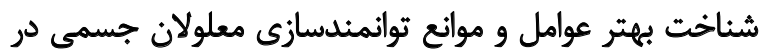

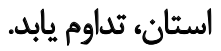

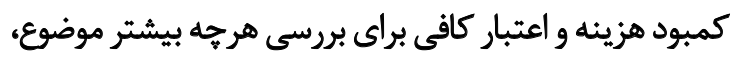

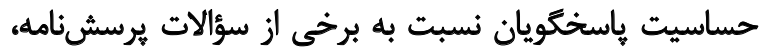

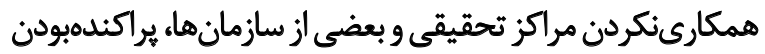

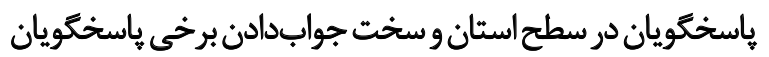

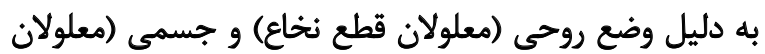

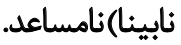

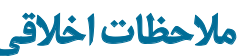

\section{ميبروى از اصول اخلاق يُوهش}

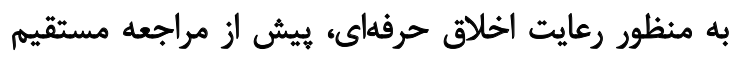

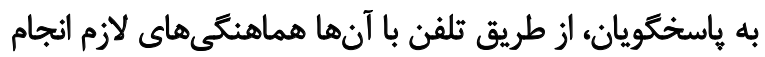

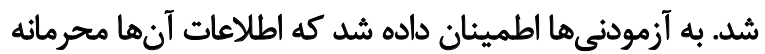

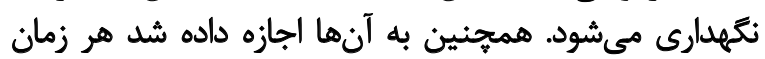
بخواهند از يُروهش خي خارج شوند.

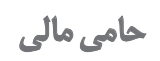

اين مقاله از هاياننامه كارشناسى ارشد وحيد دستيار در كروه

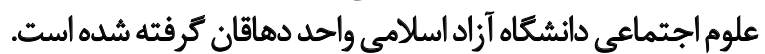

$$
\text { مشاركت ثويسند مكّان }
$$

مفهومسازي: تمام نويسندكان؛ روش شناسى: تمام نويسندكان؛

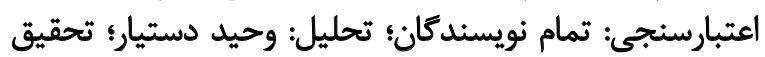

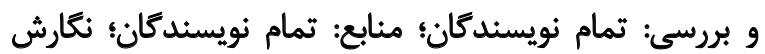

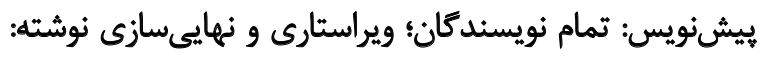

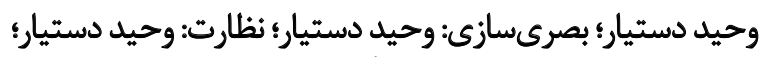

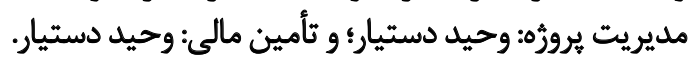

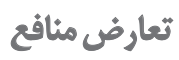
بنابه اظهار نويسندكًان، اين مقاله هيجكّونه تعارض منافعى ندارد. 


\section{References}

[1] World Health Organization. World report on disability. Geneva: World Health Organization; 2011.

[2] Karimi Dermani HR. [Rehabilitation of special groups with emphasis on services of social work (Persian)]. Tehran: Roshd; 2017.

[3] Sattari B, Omidvar K, Ya'ghoubi V. [Measurement of attitude of rural families with handicapped member(s) towards handicappeds in fields where Community Based Rehabilitation (C.B.R.) has excuted with those who has not (Persian)]. Archives of Rehabilitation. 2005; 6(3):25-32.

[4] Ahmadi H, Dastyar V, Zadebagheri L. [The influence of marriage on an empowerment of physically-handicapped people (physicalmotor handicapped ones, visceral, sensory disabilities) with mediation of social capital (Case study: Physically-handicapped people supported by the Social Welfare Organization of Kohgiluyeh Boyer-Ahmad province) (Persian)]. Journal of Participation and Social Development. 2017; 2(4):79-113. [DOI: http://jpsd.hormozgan.ac.ir/article-1-84-fa.html]

[5] Heydari Poor M, Mashhadi A, Nekah A, Mohsen S. [Relationship between personality characteristics, emotional intelligence and quality of life mental health of people with disabilities (Persian)]. Archives of Rehabilitation. 2013; 14(1):40-9.

[6] Lucas Carrasco R, Eser E, Hao Y, McPherson KM, Green A, Kullmann L. The Quality of Care and Support (QOCS) for people with disability scale: Development and psychometric properties. Research in Developmental Disabilities. 2011; 32(3):1212-25. [DOI:10.1016/j.ridd.2010.12.030] [PMID]

[7] Davarmnesh A, Barati Sade F. [Introduction to principles of rehabilitation of the disabled persons (Persian)]. Tehran: Roshd; 2007.

[8] Brown RL, Turner RJ. Physical disability and depression: Clarifying racial/ethnic contrasts. Journal of Aging and Health. 2010; 22(7):977-1000. [DOI:10.1177/0898264309360573] [PMID]

[9] Shaditalab z. [Development and challenges of Iranian women (Persian)]. Tehran: Nashreghatreh; 2002.

[10] Kord BA. [Review on relative factors of employees empowerment of SMES (Persian)]. Management Researches. 2012; 5(15):113-34.

[11] Ostadian Khani Z, Fadie Moghadam M. [Effect of acceptance and commitment group therapy on social adjustment and social phobia among physically-disabled persons (Persian)]. Archives of Rehabilitation. 2017; 18(1):63-72. [DOI:10.21859/jrehab-180163.]

[12] Akbari Z, Momeni Mahmoie H. [Empowerment of the blind persons (Persian)]. Paper presented at: $3^{\text {th }}$ National Conference on Psychology and Behavioral Sciences. 13 August 2015; Tehran: Iran.

[13] Ahmadi H, Dastyar V, Zadebagheri L. [The influence of marriage on an empowerment of physically-handicapped people (physicalmotor handicapped ones, visceral, sensory disabilities) with mediation of social capital (Case study: Physically-handicapped people supported by the Social Welfare Organization of Kohgiluyeh Boyer-Ahmad province) (Persian)]. Journal of Participation and Social Development. 2017; 2(4):79-113.
[14] Ghafarpoor Nafchi S, Mohammadi A. [Effective factors contributing to acceptance of people with disability in the society (Case study: Shahrekord) (Persian)]. Archives of Rehabilitation. 2017; 18(3):202-11. [DOI:10.21859/jrehab-1803202]

[15] Khosravi Tapeh N, Raheb G, A'rshi M, Eglima M. [The Relationship evaluation between physical disabled's social support and life quality in Raad's Education Centres (Persian)]. Archives of Rehabilitation. 2015; 16(2):176-85.

[16] Dastyar V, Mohammadi A. [The relationship between commiseration toward the physically handicapped people (physicallymotor, sensory and visceral disabilities) and their empowerment: A case study on physically disabled persons under the support of Welfare Organization of Kohgiluyeh and Boyer-Ahmad Province (Persian)]. Paper presented at: $3^{\text {rd }}$ World Conference on Psychology, Education, Law and Social Sciences at the Beginning of $3^{\text {rd }}$ Millennium. 10 November 2016; Shiraz, Iran.

[17] Ghasemi Barghi R, Hassanzadeh Ghulam G, Javadi M, Asadi M, Bayat B, Saiepour N, et al. [Determination of views of disabled person and their families than disability in family in the Qazvin and Karaj (Persian)]. Payavard-e Salamat. 2011; 5(2):71-7.

[18] Piltan FS, Qaneie F. [A sociology study of effective factors in public health; Case Study: students of the universities of Jahrom (Persian)]. Sociological Studies of Youth. 2012; 2(5):73-94.

[19] Abbasi S, Abtahi H. [The empowerment of the staff (Persian)]. Tehran: Institute for Researches and Education of Management; 2007.

[20] Putnam RD, Leonardi R, Nanetti RY. Making democracy work: Civic traditions in modern Italy. [Delforuz MT, Persian trans.]. Tehran: Sociologists Publications; 2013.

[21] Wakefield SE, Poland B. Family, friend or foe? Critical reflections on the relevance and role of social capital in health promotion and community development. Social Science \& Medicine. 2005; 60(12):2819-32. [DOI:10.1016/j.socscimed.2004.11.012] [PMID]

[22] Fatehi A, Ekhlasi E. [Factors affecting social capital: A case study of female pre-university students of Shiraz (Persian)]. Social Development \& Welfare Planning. 2013; 4(14):145-82.

[23] Naderian Jahromi M. [Sociology principle in sports (Persian)]. Tehran: Bamdad Ketab; 2016.

[24] Aboutalebi H, Jafari Harandi M, Ayati SMR. [Jurisprudential foundations of fitting (making appropriate environments) for the disabled People (Persian)]. Social Welfare. 2017; 17(65):235-65.

[25] Azad Armaki T. [The theories of sociology (Persian)]. Tehran: Soroosh Publication; 2013.

[26] Spreitzer GM. Social structural characteristics of psychological empowerment. Academy of Management Journal. 1996; 39(2):483-504. [DOI:10.5465/256789]

[27] Conger JA, Kanungo RN. The empowerment process: Integrating theory and practice. Academy of Management Review. 1988; 13(3):471-82. [DOI:10.2307/258093] 
This Page Intentionally Left Blank 